\title{
Flavonoid-Dihydroquercetin in Nutrition of Man and Animals, Safety of Agricultural Products
}

\author{
Fomichev $\mathrm{P}^{*}$ \\ Doctor of biological Sciences, Centre for Animal Husbendry, Russia
}

Received: December 28, 2017; Published: January 09, 2018

*Corresponding author: Fomichev P, Doctor of biological Sciences, Professor, LK Ernst Federal Science Centre for Animal Husbendry, Russia, Email: fomichev@yandex.ru

\section{Opinion}

In recent decades, as noted by the world health organization, growing threat is posed by the problem of microbial resistance arising unjustified use of antibiotics in medicine and animal husbandry. Scientists in the US, the UK and China call on UN to convene a session to discuss the issue and action to combat "supermicrobs", sharply reduce the use of antibiotics in medicine and farming. Otherwise by 2050 the 10 million people a year will die from infections that cause antibiotic-resistant bacteria. At the same time in the world, including Russia, actively developing ecological agriculture. According to forecasts by 2020 the global market for ecological (organic) products can achieve a turnover of 200-250 billion dollars a year. Under environmentally friendly agricultural products understand the products that are within the adopted for the various types of life-cycle (production-processingconsumption) complies organoleptic, hygienic, technological and toxicological regulations and no negative impact on human health, animals and the environment. In Russia prepared a draft law on organic agriculture, for the first time recorded, what can be called organic products. This product is obtained from healthy animals and plants, without the use of agrochemicals, pesticides, antibiotics, genetically modified organisms that have not been subjected to treatment with ionizing radiation.

Adopted GOST R 56508-2015 “organic Products. The rules of production, storage, transportation. "with the introduction of 01.01.2017. In this regard, there is a need of search for new natural bioregulators of organisms that provides high resistance of animals to the effects of biotic and abiotic environmental factor, safety, high reproductive ability and the realization of the productive potential of the animal. These properties are natural substancesbioflavonoids-this is a diverse group of plant polyphenolic compounds, the structure of which is diphenylpropanoic carbon skeleton. In plants found to contain more than 4,000 flavonoids identified chemical structure. Bioflavonoids can be used for the synthesis of biologically important compounds in the cell (e.g., ubiquinone). Rutin and quercetin-polyphenols with P-vitamin activity are effective antioxidants. Flavonoids (catechins) of green tea can exert pronounced cytoprotective effect, which is based on their ability to neutralize free radicals. Unlike vitamin E, bioflavonoids in addition to direct anti-radical action may also bind metal ions with variable valence, inhibiting, thus, the process of lipid peroxidation of membranes.

Damage to the structural integrity of cells (biomembranes) causes' excessive activation of free radical oxidation and the formation of its toxic products, which ultimately leads to loss of productivity and natural resistance in animals and in certain conditions becomes a primary or secondary pathogenetic link of the disease. One of the most studied flavonoids is dihydroquercetin with a wide range of biological properties; regulates metabolic processes, has a positive effect on the functional state of internal organs of the body, creates mechanisms to protect healthy cells from pathologies caused by chemical poisoning, exposure to electromagnetic radiation and radiation by neutralizing radical activity, processes of viral and bacterial nature. It is non-toxic, harmless, has a high activity at low concentrations, resistant to thermal and mechanical stress. Recognized as the standard antioxidant and is widely used in medicine and food industry. Dihydroquercetin is currently used in more than 100 biologically active food supplements and medicines, as well as in food and cosmetic products that are susceptible to oxidation.

Dihydroquercetin is also necessary for animals, especially when breeding and production of livestock in anthropogenic heavy metals ( $\mathrm{Pb}, \mathrm{Cd}, \mathrm{As}, \mathrm{Hg}$, etc.) and radionuclides (90Sr, 137Cs), the territories, and is also vulnerable to pollution, industrial chemical, metallurgical, petrochemical and other industries. Introduction in the diet of farm animals and poultry "Ecostimul-2" has a positive effect in immunodeficient condition, broncho-pulmonary pathology and the violation of the functional state of the liver, etc., which is usually the result of exposure to the adverse factors of environment and technology, inadequate physiology of farm animals. Thanks to the activity and antioxidant properties of dihydroquercetin significantly improved metabolism on the border of the cell and the capillary and increasing the antioxidant status of the organism. 
Antioxidant action of dihydroquercetin, like other flavonoids, is one of nonspecific mechanisms of realization of many other biological properties. Currently, conducted extensive research on the effectiveness of dihydroquercetin in dairy cattle breeding, pig breeding, poultry farming, beekeeping, rabbit breeding and fur farming. Efficiency of its application in the areas contaminated by radionuclides and heavy metals in dairy cows and calves was shown to increase the excretionxenobiotics, resistance and productivity of animals. The positive influence of dihydroquercetin on the animal organism as manifested in the period of unfavorable environmental factors, and in the period of technological factors.

The unique properties of dihydroquercetin allows to use it extensively in the food industry to:

a. Increase periods of storage of raw materials for the production of food products themselves and foods containing fats;

b. Make food products for therapeutic and prophylactic qualities;

c. Increase shelf life of fats and vegetable oils;

d. Increase the shelf life of milk powder, condensed milk and other milk products, in particular cream, ice cream, sour cream, yogurt, and also prevents vegetables, fruit and products of their processing from darkening and premature decay.

The use of dihydroquercetin in fat-containing foods prolongs their shelf life several times and gives them a pronounced relaxation properties, the consumption of such products gently increases the activity of the immune system a natural and physiological way. Dihydroquercetin is introduced into the composition of food products is especially necessary for people living in ecologically disadvantaged areas. Regular consumption of foods with dihydroquercetin protected the liver from damage by viruses and various toxic substances, toxins, radionuclides and salts of heavy metals naturally. Currently being developed by GOST 33504-2015, Dihydroquercetin, TU., which is introduced from 01.01.2017 G. Research on the use of drugs on the basis of dihydroquercetin conducted in the farms of the Bryansk, Tula and Yaroslavl regions contaminated by radionuclides after the Chernobyl accident, heavy metals, oxides and other xenobiotics as a result of emissions of the metallurgical, petrochemical and paint industry, and relatively environmentally safe Moscow region.

a) The use of "Ekostimul1" in the diet of cows by breeding them in Novozybkov district of the Bryansk region contaminated by radionuclides allowed to increase nonspecific resistance of the organism to reduce the content of $137 \mathrm{Cs}$ in milk in 1,45 times, and increase average daily milk yield of 2.5 liters with a simultaneous increase in the content of fat in milk, which allowed us to obtain regulatory in environmental safety of milk and net income from the sale of the additional milk yield in the amount of $130,9 \%$ relative to control cows.

b) On the farm of the Tula agricultural research Institute, located in Plavs'ke area contaminated with radionuclides and heavy metals used in feeding cows "Ekostimul-1" allowed to reduce the $137 \mathrm{Cs}$ content in milk from $2.81 \mathrm{~Bq} / \mathrm{kg}$ to the level of the minimum detektorami activity and the lead content of milk of cows and to normalize carbohydrate and fat metabolism in the body (patent RU 2328132 S2).

c) Inclusion in the diet of highly productive cows "-Ekostimul -1 " on the farm "Dubrovitsy" Moscow regeon allowed to increase the average daily milk yield from $31.4 \mathrm{~kg}$ to $34.7 \mathrm{~kg}$, or $10.6 \%$, to get additional profit of 792 rubles. per cow per month, normalize carbohydrate and fat metabolism.

d) FA «Ekokor» designed for use in periparturient period for prophylaxis and correction of disorders of carbohydrate and lipid metabolism, clinical, subclinical acidosis and ketosis, disorders of function and fatty degeneration of the liver; stress and free radical oxidation of lipids, disorders of cardiovascular system and microcirculation in the central nervous system, the glands, including the breast, and tissues of the body; and increasing antioxidant protection of the organism; reproductive ability, milk productivity and period productive use of cows (patent RU 2454228 S2).

e) As a result of prophylaxis and correction of above violations and pathologies in the organism of cows in the periparturiend period when the Ekokor was givenat cow have more fully implemented the genetically determined productivity potential and improve the productive health that is expressed in receiving additional 500-700 kg of milk of natural fat in 305 days of lactation, which ultimately contributes to the branch profitability by $25-30 \%$.

f) Application of "Ekostimul1" for growing calves suckling period in conditions of contamination of environment by radionuclides and heavy metals has reduced the degree of resorption from the intestine of radionuclides $90 \mathrm{Sr}, 137 \mathrm{Cs}, \mathrm{Pb}$ and $\mathrm{Cd}$ in 2, of 1.9, 1.5 and 200 times, respectively, resulted in calves that received feed additive, increased the level of resistance that contributed to the average increase for 6 months for $838 \mathrm{~g}$, which was higher than in the control at $3 \%$.

g) Experience on calves held in JSC "Krasnaya Poyma", located in Moscow region, when watering of milk acidified with formic acid with the addition of "Ekostimul-2" increased calf vitality and enabled to obtain the average daily gain over the first 50 days of $864 \mathrm{~g}$ and a subsequent 50 days to $1113 \mathrm{~g}$, which was more than in control 13.1 and $10.5 \%$ respectively.

h) The economic efficiency of growing calves when applying Ekostimul-2 702,2 amounted to RUB on the head or 11.9 RUB. on 1 RUB. of the cost of a feed additive.

i) In the studies carried out on the farm "Dubrovitsy" in Moscow regionand the use of probiotics in Tokarina and Carolinavacation together with Ecostimul-2, with nursing it is impossible calves acidified with formic acid of milk were received daily gain $817 \mathrm{~g}$, which was greater than the control at $100 \mathrm{~g}$ and more in the group of calves treated with probiotics at $26 \mathrm{~g}$. The result was obtained 2.3 and 1.7 roubles of profit per 1 ruble of the costs. 
j) The use of food additives Ecostimul-1 and Ecostimul-2 when growing suckling piglets and weaners was also costeffective. UsingEcostimul1 separately and in conjunction with probiotics Tokarina and amilovarina contributed to the reduction of disorders of the gastrointestinal tract 2.5 times at $100 \%$ of safety stock, as well as increasing the average daily gain of 21.3 and $15.9 \%$, respectively, when joint with probiotics and individual application of Ecostimul-1. The economic effect from the use of this composition was 16.5 and $13.8 \%$, respectively relative to the control.

k) When growing pigs after weaning at 60 days of age on the same farm Ecostimul-1 was also effective. With 100\% preservation of average daily gain reached $540 \mathrm{~g}$, which was higher than in the control by $21.8 \%$.

l) In other studies on piglets weaned within 52 days, on the full grown animal feed SK-4 and SK-5 with the addition of -Ecostimul2" separately and together with arabinogalactan, the average increase amounted to 496 and $504 \mathrm{~g}$, respectively, at $100 \%$ of safety, which was higher than in the control by 20.6 and $22.6 \%$ respectively at $90 \%$ intact.

m) A particularly high efficiency of Ecostimul2 and arabinogalactan appeared in the period of extreme environmental heat - July-August 2010, when the pig farm was the temperature during this time at $+30^{\circ} \mathrm{C}$, and the air was present "smog". During this period, average daily gain when giving Kostial-2 and arabinogalactan was 618 and 570 g when fully intact, which was higher than in the control group, 38.8 and $28.1 \%$ respectively, and in $70 \%$ of safety stock?

n) When using FAEcostimul1 and 2 and arabinogalactan during a full cycle of growing and fattening the live weight of $100 \mathrm{~kg}$ pigs was achieved at 193 and 203 days, which was lower by 53 and 43 days, compared to the control. With all indicators of the quality of carcasses and pork were significantly superior to control. The result is economic efficiency in the use of FA Ecostimul 2 and arabinogalactan amounted to 8171799 and RUB on the head for the period of growing and fattening.

o) Studies on the use of "Ecostimul-2" on the chickensbroilers was carried out on experimental base of Orenburg SAU.

During the 42-day growing period the average daily live weight gain was gradually increased, reaching a six-week age of $53.86 \mathrm{~g}$, in the group of chickens treated with "Ecostimul2" and 49,75 g in the control group. The result is the live weight of the broiler at the end of cultivation amounted to $2208 \mathrm{~g}$ with $93 \%$ intact when included in the diet "Ecostimul-2", which was more by $8.27 \%$ compared to the control group at $85 \%$ intact.
The use of FAEcostimul-2 and arabinogalactan in the cultivation and industrial use of laying hens was also positive. Analysis of productivity of laying hens showed that the average egg weight in the group receiving Ecostimul2, exceeded the control values by $2.71 \%$, in addition, it increases the egg production of birds of the experimental group by $1.37 \%$. Along with this increase the cost of feed for 1 hen for the entire experimental period by $0.72 \%$. Distribution of eggs by categories shows that the bird experimental group more intensively increases productivity with age. As early as 26 weeks of age, the proportion of eggs of I category is more than $58 \%$ of the total weight, whereas in the control group of this level reached only by the age of 28 weeks.

Between 25 - to 43-week-old birds from the experimental group received from 8,92 to $9.64 \%$ of eggs with an average weight of $75 \mathrm{~g}$, while in the control group eggs of the highest category by weight was only in the period from 23 to 29 weeks of age and not more than 3.03 percent of the total number of eggs. High efficiency of application "Ecostimul-2" was obtained in beekeeping. Bee families was provided in drinking bowls water solution Ecostimul-2 at a concentration of $5 \mathrm{mg} / \mathrm{l}$ in early spring exposure hives after wintering for two months before the main honey flow, stimulated oviposition by the Queen, which was made in the experimental group 1429 eggs a day, which was more than in control of $16.0 \%$. With the fecundity of females is positively correlated honeyproduktivnost bee colonies. The food industry digidrokwertitin used in two ways: As an antioxidant, which allows to increase the shelf life of the product. The use of digidrokvertsetina in the dairy industry due to the fact that it prevents the process of oxidaitionfood and increases the duration of their shelf life in 1.5 - 4 times, retains the original organoleptic characteristics for a longer time. For example, the shelf life of the yogurt increases to 60 days, the mayonnaise for up to 30 days, ice cream 2-3 times sour up to 40 days of cheese melted to 120 days, products.

Made of dried milk with fat content of $25 \%$ by $1.5-2$ times, milk powder, , soy - milk concentrate - up to 12 months, cottage cheese freeze dried-2 times. Dihydroquercetin contributes to the inhibition of the process of the growth of microorganisms in the finished product. In particular, has an inhibitory effect on Staphylococcus aureus (S. aureus), $90 \%$; lipolytic microorganisms from 44 to 88\%; bacteria L. monolcytogenes $30 \%$, E. coli $12 \%$. ; inhibits wild yeast of the genus Rhodotorula, lactic acid bacteria and bacteria of the group Aicyclobacillusacidoterrestris. At present time Commition implemented decision (EU) 2017/2079 of 10 November 2017 the authorizing the plaicing on the market of taxifolin-rich extract as a novel food ingredient under Regulation (EC)№258/97 of the European Parlament of the Council (noptified-under-document C (2017) 7218) (Official journal of European Union L*295/81/). 


$\begin{array}{ll}\text { BIOMEDICAL } & \text { Assets of Publishing with us } \\ \text { RESARCAIES } & \text { Global archiving of articles }\end{array}$

